\title{
Современные геологические процессы
}

\section{АКТИВНОСТЬ ВУЛКАНА КЛЮЧЕВСКОЙ В НОЯБРЕ 2019 - ИЮНЕ 2020 ГГ.}

Вулкан Ключевской - самый высокий действующий вулкан Евразии, входит в состав Ключевской группы вулканов (рис. 1). Это вулкан-гигант, на его долю приходится почти половина ювенильного материала, поступающего на поверхность земли в Курило-Камчатской вулканической зоне (Озеров, 2019).

Научные наблюдения за активностью вулкана проводятся с 1930-х годов (Пийп, 1956). На протяжении последних 20 лет вершинные извержения вулкана происходят в среднем один раз в 2-4 года. Предыдущее извержение продолжалось с 19.03.2016 г. по 04.11.2016 г., было субтерминальным и сопровождалось обвалом пород в Апахончичском желобе (рис. 1) (Гирина и др., 2019). После окончания извержения 2016 г. на вершине вулкана образовался кратер-провал диаметром около 100 м и глубиной порядка 300 м. Его объем, по нашим оценкам, был равен примерно $0.003 \mathrm{KM}^{3}$.

16 февраля 2019 г., по сейсмологическим данным, началась активизация вулкана (вулканическое дрожание (ВД) и землетрясения 4-го типа) ${ }^{1}$. По спутниковым данным, в кратере 1 ноября впервые была отмечена термоаномалия, а примерно через 10 дней отмечено лавовое озеро. С 11 ноября 2019 г., по видео- и визуальным наблюдениям из пос. Ключи, наблюдалось свечение над кратером и происходящие стромболианские взрывы. Это позволяет считать 11 ноября днем начала нового вершинного извержения Ключевского вулкана и говорить о том, что с ноября 2019 г. в кратере накапливалась лава и пирокластика.

В период с декабря 2019 г. по февраль 2020 г. над кратером постоянно отмечались свечение и слабая стромболианская активность, а с начала февраля отношение амплитуды к периоду ВД на сейсмостанции «Цирк» (c/ст. CIR) возросло с $(\mathrm{A} / \mathrm{T})_{\max }=0.5-2$ до 3-5 мкм/c.

С начала марта до середины апреля 2020 г., по наблюдениям из пос. Ключи, на фоне умеренной

\footnotetext{
1 Здесь и далее, используются сейсмологические данные из Единой информационной системы сейсмологических данных, Камчатский филиал ФИЦ

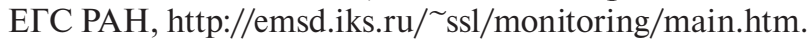

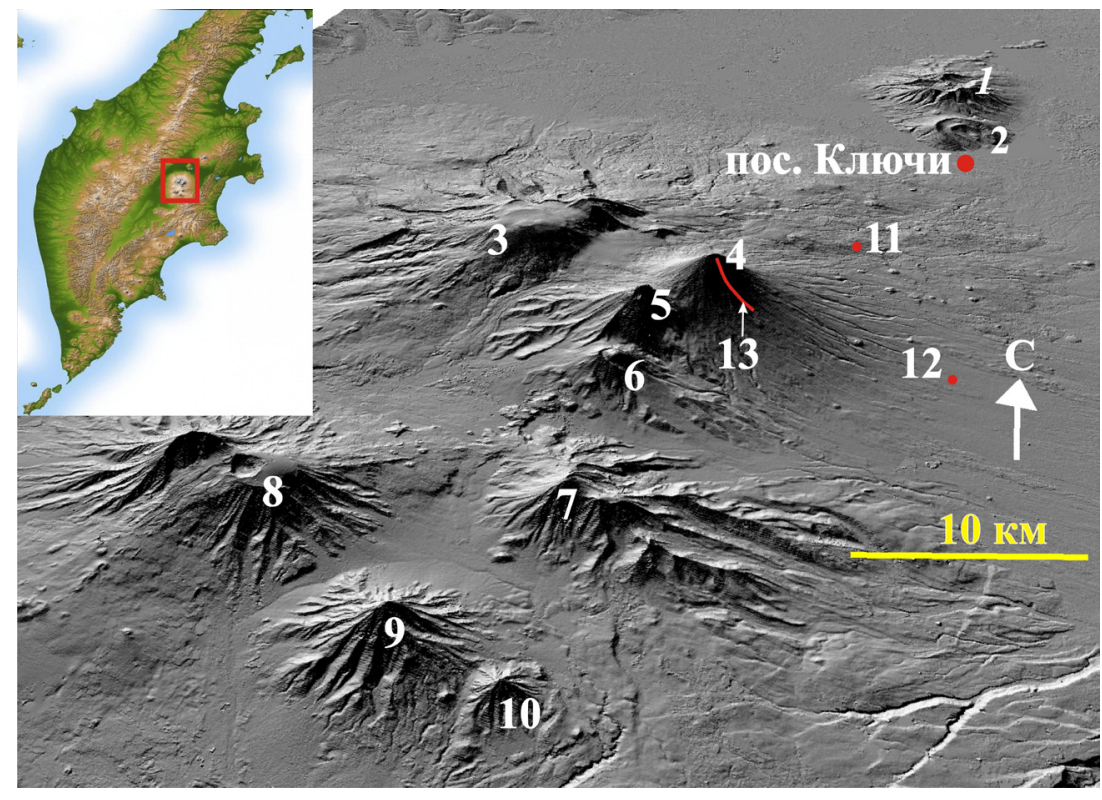

Рис. 1. Схема расположения Ключевской группы вулканов. 1-10вулканы: Харчинский (1), Заречный (2), Ушковский (3), Ключевской (4), Камень (5), Безымянный (6), Овальная Зимина (7), Плоский Толбачик (8), Большая Удина (9), Малая Удина (10); 11 - сейсмостанция «Цирк» (CIR), 12 - стационар «Апахончич», 13 - Апахончичский вулкано-тектонический желоб.

Fig. 1. Volcanoes of the Klyuchevskaya group. 1-10 - volcanoes: Kharchinsky (1), Zarechny (2), Ushkovsky (3), Klyuchevskoy (4), Kamen (5), Bezymianny (6), Oval'naya Zimina (7), Plosky Tolbachik (8), Bolshaya Udina (9), Malaya Udina (10); 11 seismic station «Circ» (CIR), $12-$ «Apakhonchich» station. 13 - Apakhonchich volcano-tectonic trough. 


\section{ЧЕРКАШИН и др.}

стромболианско-вулканской деятельности Ключевского вулкана происходили кратковременные усиления и ослабления активности в вершинном кратере. Например, 8 марта наблюдалось резкое усиление частоты и мощности стромболианских и вулканских взрывов. В ночное время в кратере происходили от 7 до 29 сильных взрывов в час с высотой выброса раскаленных лавовых фрагментов до 100-500 м над кратером, а также более слабые взрывы (по наблюдениям видеокамер Института вулканологии и сейсмологии ДВО PAH, KVERT). Как правило, раскаленный материал в заметном объеме скатывался на внешние склоны конуса до высоты 3500 м над уровнем моря. В это время происходило интенсивное отложение крупных лавовых фрагментов и, возможно, пепла на склоны вулкана. В дневное время наблюдались отдельные пепловые выбросы высотой до 2300 м над уровнем кратера.

C середины марта ВД на с/ст. CIR (рис. 1) скачкообразно возрастало до $(\mathrm{A} / \mathrm{T})_{\max }=10-20$ мКм/с и 10 апреля достигло своего максимума $(\mathrm{A} / \mathrm{T})_{\max }=31.68 \mathrm{MKM} / \mathrm{c}$, после чего постепенно пошло на спад.

17 апреля 2020 г. активность Ключевского вулкана находилась на умеренном уровне, над кратером наблюдался шлейф белого цвета, распространявшийся на высоте до 500 м в C-B направлении. 18 апреля 2020 г. с 19:47 до
20:02 местного времени серией обвалов была разрушена Ю-В стенка кратера. Обвалы сопровождались образованием обширных пеплопарогазовых облаков над Ю-В склоном. Это, предположительно, произошло из-за давления накопившейся в кратере лавы. В результате началось излияние нового лавового потока в юго-восточном секторе вулкана, в Апахончичском желобе, которое продолжается и в настоящее время.

В первые дни движение лавового потока сопровождалось фреатическими взрывами от взаимодействия со льдом, покрывающим склоны вулкана (рис. 2), с образованием протяженных грязевых потоков (лахаров). Также происходили мощные обвалы и камнепады, связанные с разрушением лавового потока извержения 2016 г. Одновременно в центральном кратере отмечались частые стромболианские взрывы с выбросом раскаленных лавовых фрагментов.

19 апреля, согласно спутниковым снимкам, протяженность потока составляла 2.8 км, азимут распространения $148^{\circ}$ (рис. 3). 21 апреля общая протяженность лавового потока от кромки кратера составляла около $1.5 \mathrm{kM}$, а протяженность отложений грязекаменных потоков 4.5 км. 23 апреля со стационара (ст.) «Апахончич» наблюдались два участка лавового потока протяженностью примерно по 300 м (рис. 4).

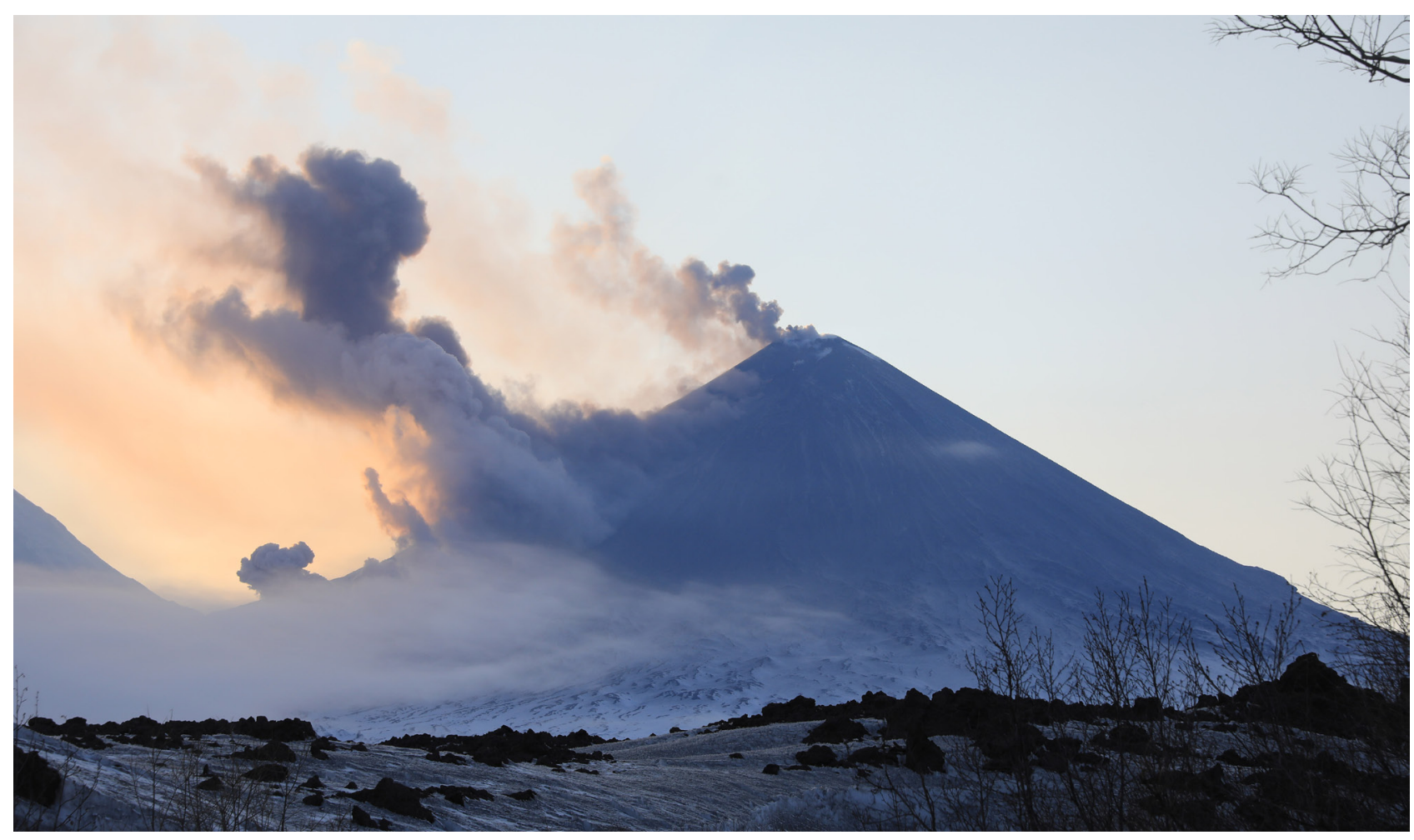

Рис. 2. Обвалы и фреатомагматические взрывы, на пути лавового потока в Апахончичском желобе. 23 апреля 2020 г. Фото Ю.В. Демянчука.

Fig. 2. Collapses and phreatomagmatic explosions on the lava flow path in the Apakhonchichsky trough. April 23, 2020. Photo by Yu.V. Demyanchuk. 

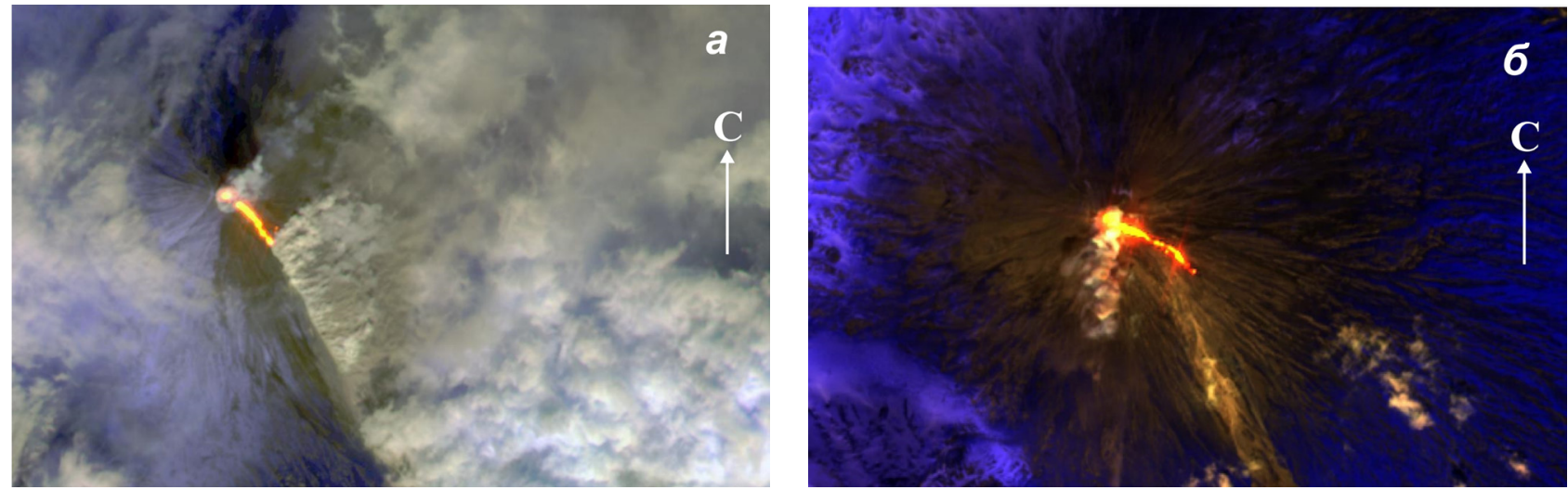

Рис. 3. Спутниковые снимки Ключевского вулкана (Sentinel-2, мультиспектрометр MSI, Европейское космическое агенство), комбинация инфракрасных каналов (SWIR), 19 апреля (a) и 14 мая (б) 2020 г.

Fig. 3. Sattelite images of the Klyuchevskoy volcano (Sentinel-2, multispectrometer MSI, European Space Agency), combination of infrared channels (SWIR), April 19 (a) and May 14 (б) 2020.

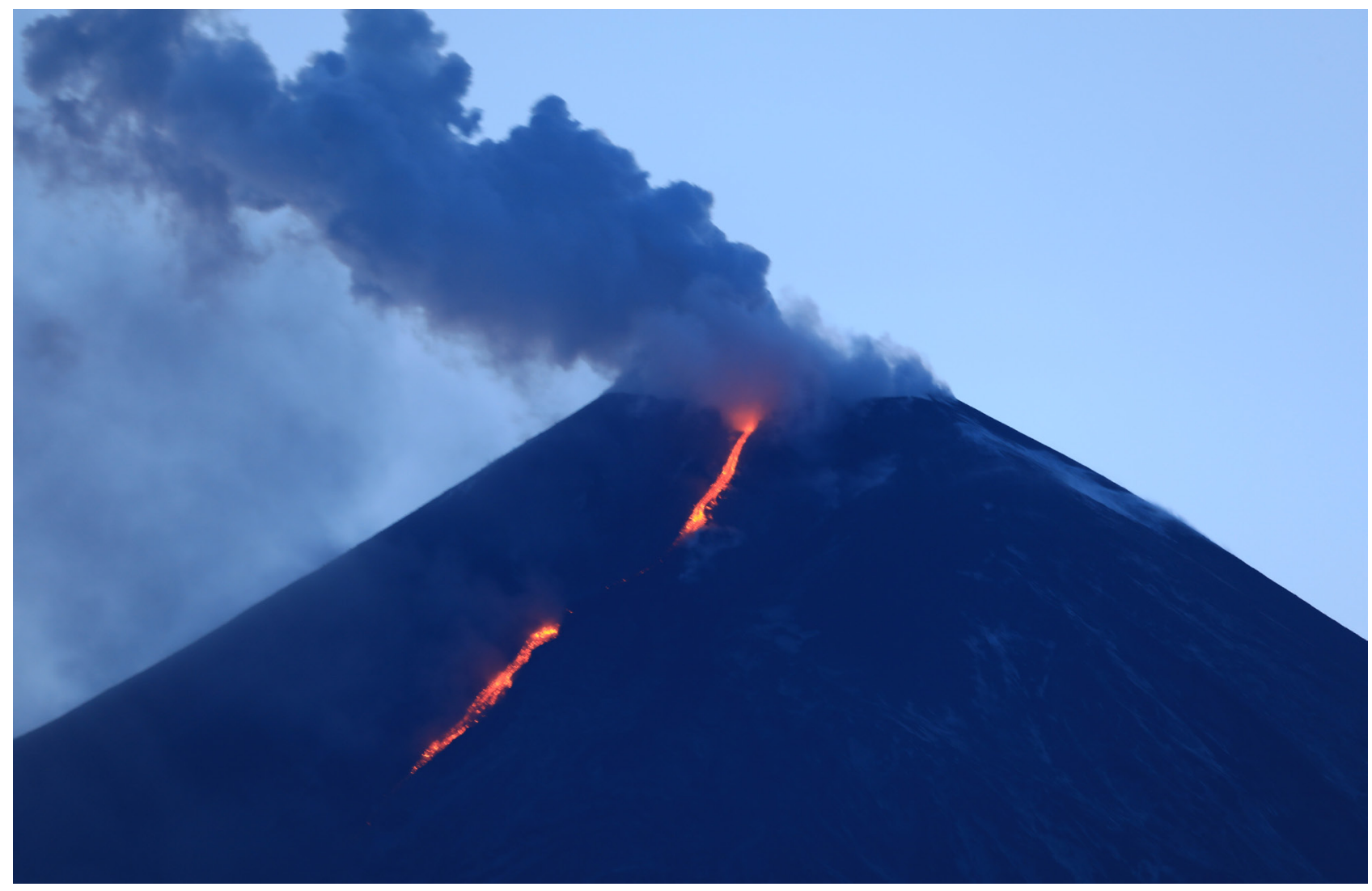

Рис. 4. Снимок Ключевского вулкана со ст. Апахончич. Лавовый поток движется по Апахончичскому желобу. 23 апреля 2020 г. Фото Ю.В. Демянчука.

Fig. 4. Klyuchevskoy volcano.View from the Apakhonchich station. Lava flow is moving along the Apahonchich trough. April 23, 2020. Photo by Yu.V. Demyanchuk

Верхний участок брал начало непосредственно из кратера, а нижний начинался на высоте 4430 м. Раскаленные обломки скатывались вниз по поверхности с фронта верхнего участка потока к нижнему. Вероятно, оба участка составляли единый лавовый поток, средняя часть которого перемещалась внутри лавовода, образовавшегося на начальном этапе развития потока.
К 12 мая, согласно спутниковым данным, на Ю-В склоне Ключевского вулкана началось формирование второго русла лавового потока, отклоняющегося к С-B от основного. 14 мая новое русло лавового потока с азимутом около $120^{\circ}$ стало основным, небольшой фрагмент лавового потока стал виден из пос. Ключи (рис. 3б). В ходе наблюдений за движением лавового 


\section{ЧЕРКАШИН и др.}

потока со ст. «Апахончич» отмечались многочисленные тонкие ответвления лавы от основного русла в различных направлениях по Ю-В склону (рис. 5, на 1 стр. обложки).

По спутниковым данным, 2 мая в восточной части кратера Ключевского вулкана было зафиксировано появление небольшого шлакового конуса. 14 мая из пос. Ключи в кратере были четко видны три центра стромболианской активности (рис. 6), как минимум два из которых относились к упомянутому шлаковому конусу в восточной части кратера. Жерло, расположенное ближе к западной части кратера (справа на рис. 6), возможно, формирует свой шлаковый конус меньшего размера, либо является западной боккой у основания шлакового конуса в восточной части кратера.По наблюдениям с ст. «Апахончич» 30 мая 2020 г., над Ю-В кромкой вершинного кратера стала видна вершина восточного шлакового конуса (рис. 7). По-видимому,

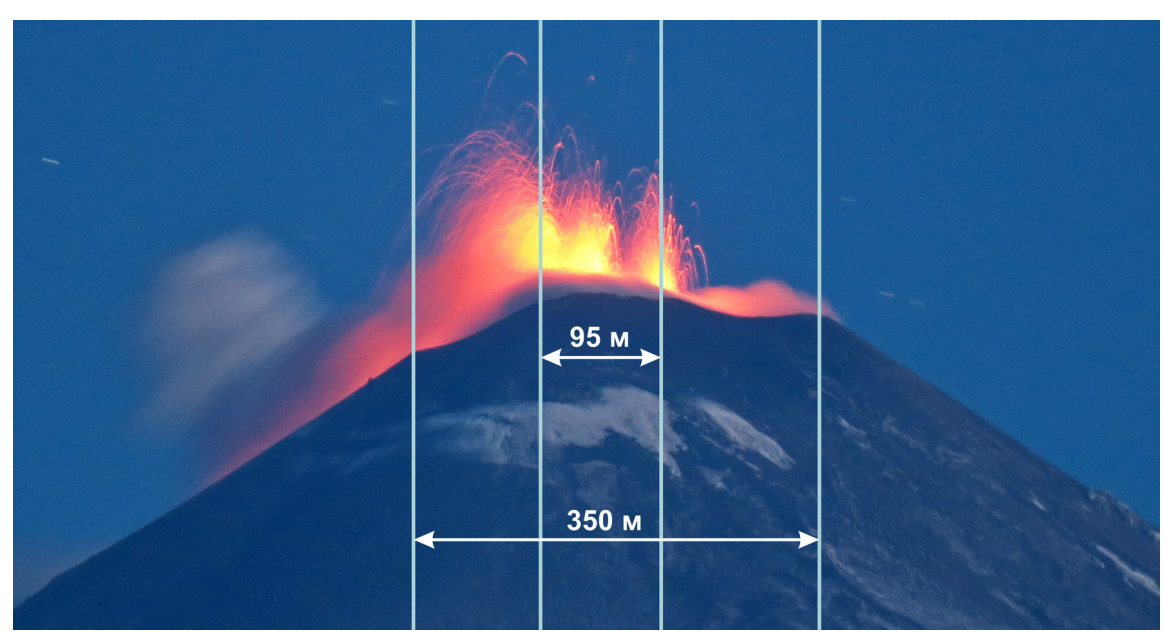

Рис. 6. Стромболианская активность в вершинном кратере Ключевского вулкана 14 мая 2020 г. Наблюдается три центра выбросов раскаленных лавовых фрагментов.Расстояние между дальними центрами - около 100 м. Фото Р.И. Черкашина.

Fig. 6. Strombolian activity in the summit crater of the Klyuchevskoy volcano on May 14, 2020. Three centers of ejections of incandescent lava fragments are observed. The further centres are located about $100 \mathrm{~m}$ apart. Photo by R.I. Cherkashin.

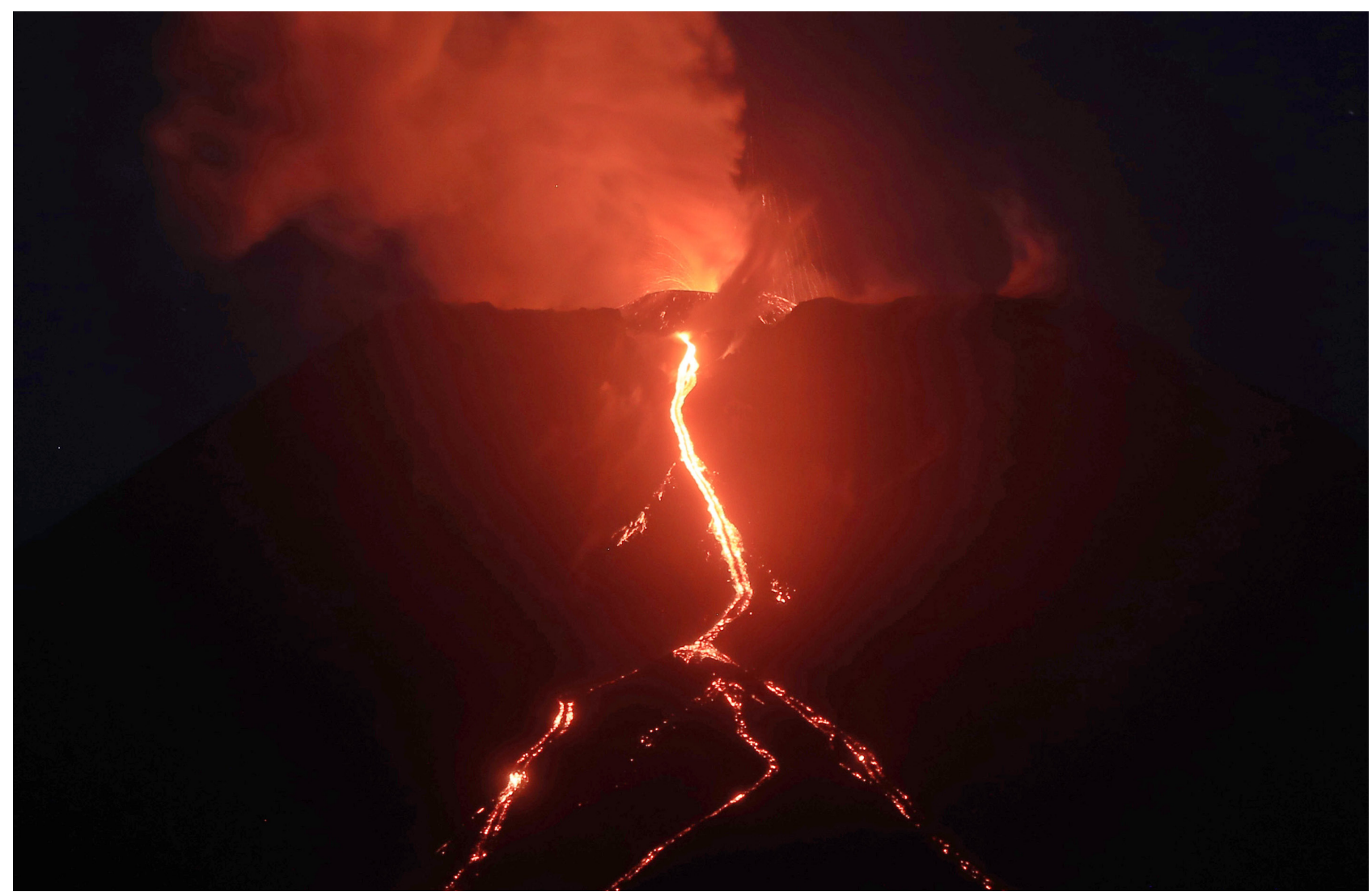

Рис. 7. Снимок Ключевского вулкана со ст. Апахончич. Над кромкой кратера виден растущий шлаковый конус. 30 мая 2020 г. Фото Ю.В. Демянчука.

Fig. 7. Klyuchevskoy volcano. View from the Apakhonchich station. Growing cinder cone is seen above the crater rim. May 30, 2020. Photo by Yu.V. Demyanchuk. 


\section{АКТИВНОСТЬ ВУЛКАНА КЛЮЧЕВСКОЙ}

лава, поступающая в Апахончичский желоб, изливалась только из одной бокки у Ю-В основания этого конуса. Его высота 30 мая составляла около 20 м, диаметр основания 140 м, а объем 165 тыс. Км$^{3}$.

В мае ВД на с/ст. CIR сохраняло тенденцию к понижению, его уровень опустился к 3 июня до $(\mathrm{A} / \mathrm{T})_{\max }=4.41$ мкм/с, однако к 10 июня наблюдается рост $(\mathrm{A} / \mathrm{T})_{\max }$ до 14 мкм/с. Вершинное извержение Ключевского вулкана продолжается.

Работа выполнена при поддержке проекта РФФИ № 19-05-00401-А.

\section{Список литературы [References]}

Гирина О.А., Маневич А.Г., Мельников Д.В. идр. Извержения вулканов Камчатки и Северных Курил в 2016 г. и их опасность для авиации // Вулканология и сейсмология. 2019. № 3. С. 34-48. https:// doi.org/10.31857/S0205-96142019334-48 [Girina O.A.,
Manevich A.G., Melnikov D.V.et al. The 2016 Eruptions in Kamchatka and on the North Kuril Islands: The Hazard to Aviation, Journal of Volcanology and Seismology. 2019. V. 13. № 3. P. 157-171]. https://doi. org/10.1134/S0742046319030047.

Озеров А.Ю. Ключевской вулкан: вещество, динамика, модель. М.: ГЕОС, 2019. 306 с. [Ozerov A.Yu. Klyuchevskoy volcano: rocks, dynamics, model // M.: GEOS, 2019. 306 p.].

Пийп Б.И. Ключевская сопка и ее извержения в 1944-1945 гг. и в прошлом. М.: Изд-во АН СССР, 1956. 312 c. [Piip B.I. Klyuchevskoy Volcano and Its Eruptions in 1944-1945 and in the Past, Moscow: Akad. Nauk SSSR, 1956].

Р.И. Черкашин, В.В. Иванов, Озеров А.Ю., Д.В. Мельников, Ю.В. Демянчук, Институт вулканологии и сейсмологии ДВО РАН

Поступила в редакцию 15.06.2020 г. 